\title{
Fronteiras e fluxos no âmbito acadêmico: Interpelações de corpos transgressores da heteronormatividade
}

\author{
Magda Dimenstein \\ Emily Mel Fernandes de Souza \\ Jader Leite \\ Candida Dantas \\ João Paulo Macedo
}

\section{RESUMO}

Objetivou-se analisar os modos de circulação, afetos vividos, fronteiras e porosidades percebidas, resistências e negociações operadas por uma estudante travesti no espaço de uma universidade pública. Recorreu-se aos estudos de gênero e sexualidade, bem como os que analisam processos de subjetivação relativos aos contextos urbanos. 0 cenário de investigação deu-se no campus de uma universidade federal e o curso de psicologia ao qual está vinculada a estudante. Metodologicamente, explorou-se uma narrativa das práticas cotidianas e dos encontros entre a estudante e o espaço da universidade durante uma semana, registrados por escrito. A análise dessa narrativa foi orientada pela perspectiva crítica do discurso. Os resultados apontam que os percursos cotidianos recortam a universidade com barreiras evidentes e revelam os limites dos espaços habitados, exigindo enorme esforço da estudante na luta pelo reconhecimento de seus direitos. Em relação ao curso de Psicologia, reconhece-se uma ausência de discussões mais efetivas sobre as questões de gênero e, em certa medida, a recorrência a modelos teóricos tradicionais que despotencializam a possibilidade de problematizar as experiências não heteronormativas.

Palavras-chave: heteronormatividade, fronteiras, processos de subjetivação, transgênero.

\section{ABSTRACT}

Frontiers and flows in the academic sphere: Interpellations of bodies that violate hetero-normativity

This study aims to analyze the circulation, experienced affect, boundaries and perceived permeability, resistances and negotiations of a transvestite student in the environment of a public university. The theoretical framework is based on gender and sexuality studies, as well as those that analyze processes of subjectivity within urban contexts. The site of investigation was at a federal university campus and the Psychology course in which the student is enrolled. Methodologically, this study used a narrative, registered in writing, of the student's daily practices and encounters at the university over a period of one week. The narrative was analyzed from the perspective of Critical Discourse Analysis. The results show that in the daily routine at the university, the student faces barriers, and they also reveal the limits of the inhabited spaces, requiring great effort on the part of the student in the struggle for the recognition of rights. In relation to the Psychology course, results show that there is a lack of effective dialogue about questions of gender, and, in some way, the recurrence of traditional theoretical models that undermine the possibility of questioning non-heteronormative experiences.

Keywords: Heteronormativity, Boundaries, Processes of Subjectivity, Transgender.

Este artigo parte do exercício de produzir uma narrativa acerca da circulação, dos movimentos, dos afetos vividos, das fronteiras e porosidades percebidas, das resistências e negociações operadas no dia-a-dia por uma estudante travesti ${ }^{1}$ no campus universitário e espaços

\section{Sobre os Autores}

M.D.

orcid.org/ 0000-0002-5000-2915

Universidade Federal do Rio

Grande do Norte - Natal/RN

mgdimenstein@gmail.com

\section{E.M.F.S.}

orcid.org/ 0000-0002-5109-5025

Universidade Federal do Rio Grande do Norte - Natal/RN emilly.fernandes.psi@gmail.com

J.L.

orcid.org/ 0000-0002-6045-531X Universidade Federal do Rio Grande do Norte - Natal/RN jaderfleite@gmail.com

C.D. orcid.org/0000-0003-4778-9400 Universidade Federal do Rio Grande do Norte - Natal/RN candida.dantas@gmail.com

J.P.M.

orcid.org/0000-0003- 4393-8501

Universidade Federal do Piauí Parnaíba/PI

jampamacedo@gmail.com

\section{Direitos Autorais}

Este é um artigo de acesso aberto e pode ser reproduzido livremente, distribuído, transmitido ou modificado, por qualquer pessoa desde que usado sem fins comerciais. 0 trabalho é disponibilizado sob a licença Creative Commons CCBY-NC.

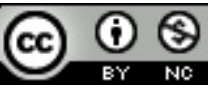


institucionais de uma universidade federal e no curso de graduação em psicologia. Situa-se na interface entre os estudos de gênero e sexualidade e aqueles que se dedicam a analisar as experiências urbanas, os processos de subjetivação na contemporaneidade, com intencionalidade de problematizar os cotidianos e nossos modos de existência e de habitar a cidade.

A inquietação que moveu a proposição dessa experiência e escrita desse trabalho foi gestada pela observação de uma série de constrangimentos sistemáticos experimentados por corpos dissensuais, por pessoas estigmatizadas, alvos de muito preconceito como é o caso da população transgênero que frequenta a universidade pública. Surpreendia-nos as dificuldades, a intolerância, a violência, ora invisível, ora manifesta, operada junto a determinados personagens frequentemente perseguidos pela expressão e afirmação de suas diferenças, em um espaço, pelo menos em tese, acolhedor à diversidade dos modos existenciais, à alteridade, às variações nos modos de estar na vida. Nosso interesse era possibilitar a produção de uma narrativa acerca das vivências desse público no âmbito acadêmico, tanto no que diz respeito à circulação no espaço físico do campus universitário e utilização da infraestrutura e dos serviços, quanto em termos da experiência no curso de psicologia, o processo formativo e a relação com os pares.

Nossa interlocutora e coautora desse trabalho era, na ocasião dessa aventura, aluna de graduação, concluinte do curso de psicologia. Inspiradas em uma perspectiva colaborativa de pesquisa e intervenção, propusemos à aluna fazer o registro ao longo de uma semana dos seus movimentos na universidade, por onde circulava, com quem se relacionava, os afetos experienciados, as situações vividas, as barreiras percebidas, os confrontos e as negociações operadas no seu dia-a-dia de estudante. Nosso intuito era conhecer seus percursos, as barreiras visíveis e invisíveis e linhas de resistências produzidas junto aos equipamentos universitários e saberes acadêmicos.

Para tanto, partimos de algumas premissas. Inicialmente, compartilhamos da ideia de que cidade é uma categoria de análise imprescindível aos estudos sobre os modos de vida contemporâneos. No atual estado do capitalismo mundial se tem a construção ideológica da cidade-mercadoria, a qual impõe certa leitura e imagem das cidades: uma representação hegemônica baseada em argumentos ancorados nas promessas de racionalidade, eficiência, organização e segurança, com vistas ao funcionamento e delimitação de padrões de vida e circulação das pessoas. São territórios de investimentos material e simbólico, de reprodução do poder político e dos lugares sociais.

A proposta dominante de organização urbana no Brasil é resultado de uma produção histórica e cultural carregada de intencionalidade e progressivamente alinhada às políticas econômicas, aos interesses de determinados grupos financeiros. Não pode ser descolada de questões como a privatização da terra, a emergência do trabalho livre, o modelo de industrialização e desenvolvimento nos últimos séculos. Esse padrão dominante de cidade veicula estilos de vida a serem consumidos, promessas e desejos, logo é uma potente engrenagem de produção de subjetividades. Sobre isso Guattari (1992) ressalta que:

As cidades são imensas máquinas - megamáquinas, para retomar uma expressão de Lewis Munford - produtoras de subjetividade individual e coletiva. O que conta, com as cidades de hoje, é menos os seus aspectos de infraestrutura, de comunicação e de serviço do que o fato de engendrarem, por meio de equipamentos materiais e imateriais, a existência humana sob todos os aspectos em que se queira considerá-las (p. 172).

O modelo de subjetividade atualmente tomado como ideal se caracteriza pela simplificação da diversidade e serialização dos modos de vida social; pela produção incessante de consensos e hegemonia em relação a uma identidade urbana única; pela pacificação das insurgências; pela imposição de uma visão de mundo com forte tônica nos ideais individualistas de sucesso, felicidade, autonomia, liberdade, autorrealização e autogoverno. Além disso, está forjada na produção contínua do medo e dos artefatos de segurança e proteção, na criação de personagens desviantes, inimigos e suspeitos, alvos de constante vigilância, encarceramento massivo e correção, assim como na criminalização das estratégias de sobrevivência desenvolvidas por aqueles considerados periféricos do sistema, com evidente associação a aspectos raciais, econômicos, de gênero e sexualidade. Em outras palavras, "a cidade produz o destino da humanidade: suas promoções, assim como suas segregações, a formação de suas elites, o futuro da inovação social, da criação em todos os domínios" (Guattari, 1992, p. 173).

A segunda premissa foi considerar os espaços institucionais acadêmicos como singularidades conectadas à complexa dinâmica urbana. Urbano entendido como modos de vida, como conceito relacional que contempla cultura, costumes, hábitos e afetos. Nesse sentido, é possível observar linhas de conexão entre esses espaços - que têm dimensionalidades territoriais e simbólicas distintas - e, consequentemente, a reprodução no espaço acadêmico da lógica hegemônica que orienta a atual organização das cidades, os estilos de circulação e as formas de habitar o espaço. De acordo com Pechman (2009), podemos dizer que o tipo de sociabilidade, de convivialidade, de relações que são vivenciadas, os limites e fronteiras que estabelecem itinerários para os corpos, as porosidades e insurgências possíveis no âmbito da cidade são 
também vividos no meio acadêmico e evidenciados através de certos discursos e práticas, de movimentos de corpos que se expressam em um espaço igualmente regulado.

A terceira premissa é que o padrão racionalista, individualista e normatizador que molda os processos de subjetivação e modos de vida atuais exige um tipo específico de corpo e formas de urbanização. Logo, processos subjetivos, corpo e urbanização são aspectos intrinsecamente relacionados, constituindo um modo de funcionamento e de existência no cotidiano. Isso quer dizer que a "maneira de ser da cidade" e a "maneira de ser na cidade" (Pechman, 2009, p. 352) constituem a mesma matéria. Guattari (1992) afirma que o porvir da humanidade parece inseparável do devir urbano.

Corpo, então, está sendo compreendido como produção histórica, como construção contínua, desnaturalizada, não linear, atravessada por forças discursivas próprias de um tempo, "superfície de inscrição dos acontecimentos" (Foucault, 1990, p. 22), sendo essa a quarta premissa em que nos ancoramos. Quando se trata de corpos que transgridem as normas de sexualidade e gênero (Bento, 2014), a exemplo de pessoas trans, a circulação na cidade e, no nosso caso, na universidade, ganha contornos diferenciados. Não é novidade que essas pessoas são marcadas por uma radical marginalidade espacial, que são afetadas por poderosos mecanismos de segregação na cidade, associados à lógica de exclusão social e reprodução da pobreza. No espaço da universidade, analogias são possíveis em relação a essa segregação amplamente produzida e planejada?

Por fim, entendemos que problematizar os cotidianos urbanos implica pôr em análise o processo de produção e apropriação do espaço, detectar diferenciais de acessibilidade desenvolvidos por diferentes grupos de sujeitos conforme marcadores de gênero, sexualidade, raça/etnia, geracionalidade, dentre outros, em tempos onde há um "alargamento indefinido dos modos de rebaixamento e monitoramento biopolítico da vida e uma imensa dificuldade em extrair desse contexto a variabilidade das perspectivas, dos modos de existência" (Pelbart, 2013, p. 13).

Nesse sentido, tomamos o cotidiano como construção social constituído, por um lado, de um feixe de forças homogeneizantes, imobilizantes e responsáveis pela manutenção dos lugares socialmente estabelecidos. Por outro lado, um cotidiano desnaturalizado, que é campo de lutas e disputas, que nos permitiria sair da impotência e imobilidade. Com base nisso, esse trabalho tem o intuito de se aproximar de um fenômeno que se evidenciou ao longo dos últimos anos nas universidades públicas, a saber: o contato com a diversidade, proporcionado especialmente pelas políticas de cotas para portadores de necessidades especiais, afrodescendentes e pelas ações afirmativas que geraram a inserção de alunos oriundos de setores sociais marginalizados seja economicamente, seja por questões étnico-raciais, com vistas a promover a efetivação de uma sociedade mais igualitária e plural e a defesa dos direitos humanos.

A questão da diversidade de gênero e sexual (lésbicas, gays, bissexuais, travestis, transexuais, transgêneros e intersexos) se encontra no escopo das ações afirmativas de combate às desigualdades e muitas instituições de ensino, atendendo ao decreto $n^{\circ} 8.727 / 2016$, já incorporaram algumas medidas inclusivas na administração pública de respeito à diversidade de orientação sexual e identidade de gênero tais como: o uso do nome social para pessoas travestis e transexuais, assistência jurídica e a utilização de banheiros por identidade de gênero, bem como o uso de uma linguagem neutra em todas as resoluções e documentos oficiais. Entretanto, a carga de discriminação e preconceito contra estudantes LGBT é assustadora tal como indicado no estudo de Costa, Peroni, Camargo, Pasley e Nardi (2015) realizado em uma universidade no sul do país, o qual detectou dentre outros aspectos a falta de uma orientação ampla em direitos humanos em todos os cursos, as tendências biologicistas e patologizantes da formação, além de altos níveis de intolerância frente aqueles que não se encaixam nos padrões de heteronormatividade.

Quando se trata especificamente da presença de travestis/ transgênero na universidade pública, seja como docente, seja como discente, a situação é ainda mais delicada, pois é um público cujo destino vem sendo historicamente a prostituição, trabalhos precários e a morte prematura por violência. No Relatório sobre Violência Homofóbica no Brasil, publicado pela Secretaria de Direitos Humanos da Presidência da República (Secretaria de Direitos Humanos, 2013) constam dados assustadores: aumento considerável das denúncias e violações; os agressores são pessoas conhecidas na maioria dos casos; travestis e transexuais seguem sendo as maiores vítimas de violência, justamente as de maior gravidade como lesões corporais e homicídios. Nesses casos, $40 \%$ dos homicídios ocorridos tiveram como vítimas as travestis. Tal documento reforça que a LGBTfobia é estrutural no Brasil, que a violência contra a população LGBT existe em níveis alarmantes e que é urgente o desenvolvimento de políticas públicas eficazes e articuladas para o seu enfrentamento pelos estados e municípios.

Instituições como a ANTRA (Associação Nacional de Travestis e Transexuais do Brasil), Rede Nacional de Pessoas Trans Brasil e a TGEU (Transgender Europe) têm sido responsáveis pelo monitoramento de violência e violação de direitos contra pessoas transgênero, vêm denunciando não só o número alarmante de assassinatos no Brasil (123 casos registrados entre outubro de 2015 e setembro de 2016), a 


\section{WIINTERACÃO EM PSICOLOGIA}

predominância do trabalho informal, assim como o ambiente escolar nocivo responsável pelo abandono de alunos nos mais diferentes níveis de ensino devido "à natureza multifacetada dos preconceitos e das práticas discriminatórias" (Madureira \& Branco, 2015, p. 589).

Sobre esse aspecto, Rondini, Teixeira Filho e Toledo (2017) alertam para a baixa quantidade ou qualidade de políticas em educação voltadas para o combate à LGBTfobia no âmbito escolar, de modo a prevalecer um modelo heteronormativo nos espaços escolares em que a diversidade sexual é tratada de modo estigmatizante. Autores como Junqueira (2010) e Franco e Cicllini (2015) discutem as várias dimensões da heteronormatividade que impregnam o currículo e os obstáculos enfrentados por professoras trans durante seu processo de escolarização e inserção na carreira docente, respectivamente. Certamente, essas pessoas são levadas a suportar as imposições heteronormativas em função da ampla vulnerabilidade a que estão expostas nos diversos âmbitos da vida cotidiana. Sabe-se que as políticas públicas voltadas para esse público não conseguem enfrentar temas caros como moradia, trabalho formal, educação e segurança pública. As que ainda se destacam são, de acordo com Toneli e Amaral (2013), as de saúde (voltadas às DST/Aids e drogas) e de prevenção à criminalidade.

Ainda que a universidade brasileira seja território histórico das elites e que nosso sistema educativo seja um dos mecanismos mais poderosos de distinção e reprodução das desigualdades sociais, ela é considerada um espaço de debate e livre circulação de ideias e pessoas, especialmente no processo de redemocratização do país, de revitalização das políticas públicas e de direitos humanos que assistimos nas últimas décadas e que vivem franca ameaça atualmente.

Considerada lugar de corpos "iguais" - onde essas enormes diferenças são neutralizadas por força dos princípios que compõem seu ethos institucional ancorado na radical defesa da democracia, do pensamento crítico e do compromisso com a formação nos planos ético-político e subjetivo - , a universidade tem como estratégia fazer da problematização o aspecto central do processo de construção do conhecimento, interrogar o instituído historicamente e desnaturalizar a realidade que, por ser sempre movente, pede um conhecimento inventivo, conectado com as forças e movimentos que estão em operação em determinada situação. No espaço acadêmico, não se trata de perseguir verdades inquestionáveis, mas conhecer como os discursos e práticas são forjados, ou seja, como e em que condições determinadas são produzidas práticas e saberes, o que criam e que realidades produzem.

Todavia, nem tudo opera nesse sentido. 0 universo acadêmico é permeado por conflitos e lutas. Não é um espaço liso, homogêneo, sem embates entre diversas concepções e pro- jetos de sociedade e de vida. Nesses tempos de controle sobre corpos e vidas, de subjetividades homogeneizadas, observa-se mecanismos cotidianos de produção de uma universidade asséptica, que "conhece" e "controla" aquilo que é perigoso, patológico, profano, sujo ou até mesmo exótico, como é o caso das pessoas transgênero, que comumente são capturadas pelas classificações e transtornos de identidade de gênero. Há, cada vez mais, tendência à conservação, ao entrincheiramento, à manutenção das formas conhecidas, aos arranjos endurecidos, repertórios em colisão e não composição. É possível identificar a divisão de espaços e fronteiras que determinam uma coreografia dos corpos e itinerários específicos, formas de controle a céu aberto (Deleuze, 2000). Há mecanismos de intolerância e não acolhimento à diferença, seja sexual, racial/étnica, econômica, religiosa.

Quanto à Psicologia, a literatura do campo tem apontado como ela se instituiu a partir da sobrevalorização da consciência, da razão, do comunicável, desvalorizando o sensível, os afetos, o corpo, o transitório, o histórico. Tem evidenciado também seu eterno combate: forças que afirmam a criação e a diferença encontram-se continuamente em luta com outras que alicerçam o pensamento positivista, saberes a-históricos e neutros, princípios dicotômicos, tecnicismo, práticas de reconhecimento de verdades estabelecidas (Dimenstein, 2007).

Isso quer dizer que em se tratando da temática da diversidade sexual e de gênero, as matrizes ontológicas, epistemológicas e metodológicas mais duras que constituem grande parte da psicologia estão em disputa continuamente com aquelas de base relacional, não essencialistas, intersubjetivas. Dessa maneira, não habitamos um terreno pacífico, ao contrário, transitamos em um nebuloso espaço constituído por um corpo de conhecimentos e práticas sobre os sujeitos, sobre o que é o normal e o patológico, alinhado às biopolíticas modernas, saberes, muitas vezes, extremamente violentos. Nossa curiosidade, portanto, era conhecer como essas questões ganham materialidade em sala de aula, nos corredores, nos conteúdos ministrados, nos encontros entre docentes e discentes, naquilo que é velado ou excluído da formação.

Contudo, a instituição acadêmica é também campo de insurgências, resistências e inventividade. É uma zona fértil de problematização. No bojo desses tensionamentos se situa esse trabalho, que objetiva narrar uma experiência de habitar territórios fronteiriços, a sensação de estrangeirismo no campus universitário e no mundo acadêmico a partir da interpelação de corpos transgressores da heteronormatividade, de corpos dissensuais que nos ajudam a rastrear as discursividades normatizantes e patologizantes, corpos que apresentam potencial político e capacidade de rearranjos do espaço público, da relação corpo-cidade, linhas de novidade, de sur- 
presa e de potência, afinal eles "montam contrariedades àquilo que é tomado por garantido" (Rodrigues, 2009, p. 19).

\section{OUVINDO E FAZENDO FALAR AS VIVÊNCIAS}

Como anunciado anteriormente, nosso cenário de investigação foi o campus de uma universidade pública e o curso de psicologia, e nosso objeto de análise, as experiências de uma estudante travesti nesse contexto. Nosso interesse era apreender os modos como esse corpo se torna conhecido, como ele entra em cena, circula e age, como é afetado e afeta seu entorno, as estratégias e táticas operadas no dia-a-dia.

Metodologicamente, propomos à aluna tecer uma narrativa escrita da sua vida de todos os dias, das práticas cotidianas, dos encontros vivenciados no espaço da universidade. Nossa intenção era que essa narrativa pudesse expor o emaranhado de forças que constituem a relação universidade/diversidade sexual. Orientados pela perspectiva da Análise Institucional (Rossi \& Passos, 2014) manejamos coletivamente essa narrativa a partir de um debate intenso entre todos os envolvidos na tentativa de produzir uma escrita cuja presença e inseparabilidade entre os autores fosse reafirmada. Isso constituiu um desafio na medida em que requereu a análise do nosso próprio atravessamento na constituição desse campo problemático e a desconstrução de certos padrões de escrita acadêmica. Dessa forma, estabelecer esse diálogo entre professores e aluna, criando efetivamente um texto de várias vozes é algo instigante que pretendemos, em outro momento, discutir mais intensamente, operando uma parada reflexiva sobre os modos de produção do conhecimento e de escrita. Pelos limites do texto, não temos a menor pretensão de abarcar todas as possibilidades de discussão que essa experiência possibilita, mas produzir uma inquietação, um certo desconforto na "incontestável" democracia institucional acadêmica.

Assim, optamos por trazer parte dessas reflexões coletivas em torno de dois eixos, os quais foram contemplados com a inserção de alguns fragmentos dessa narrativa: um referente à circulação e uso do espaço institucional da universidade (tais como bibliotecas, reitoria, residência e restaurante universitários, serviços de atenção estudantil, banheiros) e outro relativo ao curso de psicologia (relação com docentes, discentes, com as disciplinas, coordenação, serviço-escola e expectativas profissionais).

\section{CIRCULACCÃO E USO DO ESPAÇO INSTITUCIONAL DA UNIVERSIDADE}

Os percursos cotidianos traçados no relato recortam a universidade com barreiras muito evidentes e revelam os limi- tes dos espaços habitados por nossa protagonista. Seu dia-adia é marcado pela frequência regular em alguns espaços considerados como refúgio, lugar de acolhimento e segurança como é o caso do Núcleo Interdisciplinar de Estudos em Diversidade Sexual, Gênero e Direitos Humanos (Núcleo Tirésias), da secretaria do curso de ciências sociais, o Núcleo de Práticas Jurídicas (NPJ), do Centro de Referência de Direitos Humanos (CRDH), do Departamento de Psicologia e do setor de aulas II. Esses dois núcleos têm indiscutivelmente uma imensa importância na sua vida. São estruturantes do seu cotidiano, constituindo-se como dispositivos "que serviram de base para meu empoderamento e emancipação", de acordo com ela. Primeiro, porque é lá onde obtém suporte jurídico, que sempre se faz necessário pela infinidade de laudos e pareceres exigidos, e de acesso a um corpo de conhecimentos qualificados sobre as temáticas de gênero e sexualidade.

Foi através do Núcleo de Práticas Jurídicas que obteve a retificação do seu nome e gênero, processo que durou três longos anos e finalizado no ano de 2015, constituindo a primeira retificação do Estado, sem cirurgia de transgenitalização, fato que impactou fortemente no movimento transgênero local. Em segundo lugar, porque são espaços de encontro com uma diversidade de pessoas que têm em comum a luta pelos direitos humanos, a causa LGBT, dentre outras pautas, ou seja, um lugar onde compartilham experiências, de aprendizado mútuo, onde não há aversão à integração das diferenças, pretensões patologizantes, desprezo em relação ao seu corpo, associações com tudo o que é "degenerado" e "impuro", onde não é tratada como um corpo abjeto: "só de saber que aqui há pessoas que não vão deixar nenhuma violência sobre minha vivência enquanto pessoa trans* se propagar, isso me dá tranquilidade e paz", diz a narradora.

A circulação por esses refúgios, entretanto, obedece uma temporalidade. Ela não se dá de forma livre. Ocorre, sobretudo, pelas manhãs, e pela tarde, no setor de aulas II, turno de funcionamento do curso de psicologia. Apesar do forte movimento de estudantes na universidade durante o período da noite, nossa protagonista evita circular por espaços os quais, em outra hora do dia, não seriam tão ameaçadores. A noite, segundo ela, está diretamente associada às práticas de prostituição, à disponibilidade para realizar programas, é o período em que mais ocorrem ações de violência, agressões e morte no âmbito da cidade, portanto, é um período do dia que inspira cuidados e recolhimento para que a violência não se instale como ato legitimado. Efeitos da ditadura da noite tão presente na vida de travestis que são coagidas a lutar pela sobrevivência e articular suas redes de sociabilidade nos espaços da rua, os quais passam a ser demonizados. Deparamo-nos, portanto, com subjetividades e corpos marcados por cicatrizes que remontam às histórias de medo, exclusão, in- 


\section{INTERACÃO EM LF PSICOLOGIA}

Magda Dimenstein, Emily Mel Fernandes de Souza, Jader Leite, Candida Santos e justiça, deslegitimação, constrangimentos e cerceamento. Sobre isso aponta: "Hoje necessariamente tive que vir pela manhã, tarde e noite, e sempre é ruim vir fora do meu horário, as pessoas que nunca me viram ficam me fitando, se cutucando, ou olhando com expressões de interrogação e fazem questão de deixar isso nítido".

A residência universitária feminina é outro espaço potente no seu cotidiano, sinônimo de segurança, tranquilidade e conforto. A sua chegada na universidade aconteceu em um momento muito conflituoso de sua vida pessoal, após ter sido expulsa de casa por sua condição, encontrando-se em evidente desamparo, situação muito comum entre a população transgênero. Essa moradia foi conquistada com muita luta contra as resistências de outras moradoras e a burocracia institucional, sendo a primeira travesti a ocupar esse lugar, as quais revelam explicitamente os preconceitos e discriminações vividos. Segundo ela, a ocupação desse espaço é um marco na sua vida e na história da própria universidade: "Eu digo que eu desbravei esse espaço, visto que ele nunca havia sido antes habitado por uma pessoa trans*, que realmente era uma fronteira bem delimitada e que realmente ter uma pessoa trans* nesse ambiente não fazia parte nem da agenda da universidade nem da agenda das estudantes que aqui moravam".

Muitas fronteiras foram detectadas na sua movimentação cotidiana pelo campus. Fronteiras físicas e simbólicas. Mesmo nos espaços considerados acolhedores como o setor de aulas II, lugares onde parece haver um maior grau de assimilação da diferença, há barreiras e divisões difíceis de superálas, indicando a presença de rumores da cidade e das lógicas segregadoras, asfixiantes e pouco porosas que observamos na contemporaneidade. Nossa narradora diz: "Acho engraçado que esse é o setor dito plural da universidade, com pessoas de diversos tipos e jeitos, pensei que não haveria tanto espanto ao ver uma pessoa trans* circulando por ele, achei que seria mais bem aceita e acolhida. Circular pelo Centro de Ciências Humanas não é diferente. Sempre há uma pessoa que vai olhar e fazer expressões curiosas e espantadas".

Na realidade, sua percepção se amplia para a universidade como um todo, reconhecendo a manutenção de tais lógicas segregadoras e excludentes em uma dimensão mais ampla que abrange a vida social como um todo, que incluem não só o gênero dos corpos, mas também referentes de classe social e de raça/etnia e religião. A dificuldade de acesso à universidade pública pela população transgênero é primeira de uma série de duras constatações.

Apesar de fazer parte de uma pequena parcela que conseguiu ingressar no ensino superior público, fruto de intensos movimentos de resistência pessoais e coletivos contra o peso dessa bagagem opressiva, de duelos familiares e sociais históricos, nossa protagonista esbarra em dificuldades como a falta de conhecimento e orientação legal dos funcionários em relação às pessoas transgênero. Relata as seguintes situações em alguns dos serviços da universidade: "Primeiro, o atendente não sabia o que era nome social e quando eu falei que era trans* ele simplesmente me olhou estupefato e eu tive que explicar o que era".

Esse descaso em relação aos direitos das pessoas transgênero revela não somente a falta de treinamento e atualização dos funcionários e de apoio em relação ao acesso ao tratamento hormonal, um dos muitos problemas enfrentados, mas especialmente a invisibilidade institucionalizada frente a essas pessoas que não gozam do status de sujeitos, de cidadãos: "As expressividades desestabilizam o cotidiano sedimentado na heteronormatividade, promovendo exclusões e cerceamento de direitos como os de saúde e educação" (Sales, Souza, \& Peres, 2017, p. 75). Corpos abjetos, que não fazem sentido, que não podem ser legitimamente reconhecidos dentro de uma matriz cultural hegemônica forjada na heteronormatividade (Butler, 2000).

Butler (2000) considera abjeto todos os corpos cujas vidas não são consideradas vidas e sua própria humanidade é questionada. Essa estranha presença na universidade induz a instituição a reproduzir e acompanhar, curiosamente, aquilo que se engendra no âmbito da cidade: a desclassificação dessas existências humanas. A violência dos discursos e práticas institucionais cumprem a função de sustentar a marginalidade desses corpos e a exclusão da condição de sujeitos, mantendo-os fora do escopo da cidadania. Tal aniquilação incita a montagem de um arsenal de afırmação e sobrevivência subjetiva, que embora fortaleça a vida dessas pessoas, como se pode observar no relato abaixo, requer um quantum de energia, de disposição e de potência para lançar o corpo para longe das paixões diminutivas e servis, do cansaço paralisante e da morte, tal como se vê na saga contada a seguir em um processo de negociação institucional:

"Então eu falei que recorreria e que citaria os artigos da carta de direitos humanos, principalmente o que fala do direito à dignidade humana e autoafirmação da personalidade.... Depois comecei a falar das leis de nível federal de nome social, das leis de nível estadual e também até a nível municipal visto que a própria cidade tem uma legislação, citei também as leis do Ministério da Saúde e da educação, também a nível judiciário no âmbito penitenciário.... fora que falei também em dano pelo constrangimento público o que caberia em danos morais e psicológicos...Me senti super feliz e sinceramente muito vitoriosa, uma sensação se alívio incalculável. Percebi que empoderamento, conhecimentos jurídicos e também o diálogo com as áreas da Antropologia, Sociologia e História fizeram toda a diferença. Pensei numa frase, famosa até: 'Conhecimento é poder!"” 
Um dos espaços onde isso mais se presentifica na universidade é o restaurante universitário. Local de circulação intensa de pessoas, de olhares, de análise e avaliação. 0 ordenamento desse espaço favorece a hiper exposição das pessoas de maneira tal que é inevitável a ampla observação dos comportamentos e o encontro com a diferença. 0 panoptismo ganha expressão máxima nesse espaço. Seu principal efeito é provocar nas pessoas a necessidade de vigilância ininterrupta de si mesmo e dos outros na tentativa de ordenar os gêneros, os corpos das pessoas e a consequente normatização das maneiras de sentir e viver, tal como ressalta: " $O$ restaurante universitário acaba por ser o que mais me aflige. Cheguei muitas vezes a passar fome do que ter que enfrentar olhares e até mesmo risos enquanto eu falo ou caminho".

Foucault (2010), em "Os anormais", traz a concepção de monstruosidade para analisar os discursos estereotipados em relação ao louco e a figura do monstro, a qual muito nos interessa aqui. A definição de monstro para Foucault articula uma dimensão biológica e outra jurídica e diz respeito a uma transgressão das leis e normas da natureza e a emergência de anormalidades corporais: "O que define o monstro é o fato de que ele constitui em sua existência mesma, em sua forma, não apenas uma violação das leis da sociedade, mas das leis da natureza. (...) O monstro é o que combina o impossível com o proibido" (p. 69).

As ideias de monstro e monstruosidade estão intimamente articuladas com toda e qualquer perspectiva de transgressão, anomalia e desvio de conduta, já que a figura do monstro não só fere as leis naturais, mas especialmente, as normas sociais, morais e políticas. Essas transgressões questionam as leis civis, religiosas e divinas. Paralelo a isso, Foucault traz outra figura, que é o indivíduo a ser corrigido, ou seja, alguém que desvia da norma e que falha ao adaptar-se à organização social. Para ele são pensadas formas de intervenção que o tragam à linha da normalidade, especialmente nos espaços cotidianos, da família, da escola e do trabalho.

O que queremos chamar atenção aqui, para além do fato de que a relação entre anomalia, patologia e crime ficou consolidada, bem como a constituição de saberes e tecnologias para lidar com esses aspectos, como foi o caso da psiquiatria, psicologia e o direito, é que tais figuras, situadas nos séculos XVIII e XIX, se mantêm na atualidade (criminosos, loucos, desviantes sexuais) e, segundo Foucault, precisam ser constantemente expostas, espetacularizadas, por sua função pedagógica, normatizante, mesmo que ao final, sejam incorrigíveis, mesmo que mesclem fascínio e asco. "O monstro passa a ser aquele que é seduzido pela 'batida do olhar', num processo que flerta com a criminalização do olhar" (Rocha, 2013, p. 4). É o que se passa na circulação cotidiana de uma aluna travesti na universidade, tal como indicado nas narrativas. Cruz (2011), ao tratar da questão dos banheiros, outro espaço intensamente problemático para as travestis e também referido por nossa narradora, indica que "a oposição binária e controlada do uso de banheiros faz parte desta lógica heteronormativa, como um elemento que compõe o dispositivo da sexualidade".

Preciado (2014) debate o modo pelo qual a organização dos banheiros - mais do que simples organização arquitetônica - funciona como tecnologias do gênero. Nesses cenários, onde a existência é posta em jogo, onde se concretiza a codificação de uma anomalia que perturba a ordem social, o mal-estar diante dessa percepção que a envenena, o ultraje diante da violência, produz fortes sentimentos de inconveniência, afetos de aversão e desejos de invisibilidade e pertencimento. Vejamos seu relato:

“O sentimento que tenho é de aversão, porque não posso fazer uma refeição em paz sem ver pessoas ao meu lado se entreolhando, tentando disfarçar para ver meu rosto....Gostaria que meu corpo fosse só mais um na multidão, que realmente fosse visto como algo comum. Esses olhares sempre me abatem e me fazem variar da apatia extrema".

Sales et al. (2017) alertam que "os corpos das travestis inventam novas formas e imagens que, embora marcados pelas demandas sociais e culturais que influenciam a construção de uma estética corporal, precisam, urgentemente, de olhares mais diversificados, menos preconceituosos" (p. 76). Nossa protagonista, para não sucumbir a esses olhares petrificados, é impulsionada a mover-se, gritar, fitar, produzir-se na revolta, forçar a ultrapassagem das tiranias históricas, recusando uma postura niilista e de esgotamento. Nessa linha intempestiva de afirmação de possibilidades existenciais e de enfrentamento dos cotidianos que se reinscrevem continuamente na patologização de sua condição, lança mão de um corpo de saberes, disponibilizados na própria universidade, nos encontros aumentativos de potência, implicando-se com novos modos de circulação do poder e da vida coletiva: "apesar de haver um banheiro unissex em meu setor de aulas, eu não o frequento, e não o faço por uma simples afirmação de meu gênero: que é o gênero feminino, muIher. Se eu sou uma mulher e me vejo como tal, então que eu possa usar o banheiro que as outras mulheres usam, não vejo diferença em mim só porque sou trans*".

Dessa forma, revela um conjunto de artimanhas no cotidiano que constituem formas de enfrentamento e resistência frente aos dispositivos de controle, aos saberes totalizantes e às espacialidades produzidas com a intencionalidade de esquadrinhar sua experiência singular em uma linha de patologização e despotencialização crescentes. Afirma-se como esse monstro, como anômalo, figura que, segundo Peixoto 
Júnior (2010), tem um caráter subversivo e desencadeador de forças, pois:

Sempre desestabiliza a representação e a identidade em suas diversas formas de expressão... não apenas tangencia cada multiplicidade, cuja estabilidade passageira ou local ele determina com a dimensão máxima provisória, mas também constitui a condição da aliança necessária ao devir, levando cada vez mais longe na linha de fuga as passagens de multiplicidades ou transformações de devir (p. 182).

\section{PRESENCA DA DIVERSIDADE DE GÊNERO NO CURSO DEPSICOLOGIA}

A presença de estudantes travestis no ensino superior é uma incógnita. Não há dados oficiais que indiquem o quantitativo de pessoas que conseguiram chegar à universidade pública no país. Contudo, a exclusão é uma evidência. Nos cursos de Psicologia do país também não há informações oficiais disponíveis sobre a presença de pessoas transgênero. Nossa protagonista foi a primeira aluna travesti da história do nosso curso em seus 40 anos de existência.

Em 2011 o Conselho Federal de Psicologia publicou o dossiê "Psicologia e Diversidade Sexual: desafios para uma sociedade de direitos" ${ }^{\prime 2}$, visando ampliar o posicionamento crítico da categoria acerca da promoção dos direitos das pessoas LGBT. Esse documento tem como marca o questionamento da psicologia como ciência heteronormativa, calcada em perspectivas identitárias e na patologização do gênero, com autoridade para determinar "limites discerníveis" entre "os transtornados de gênero" e "os normais de gênero" (Bento, 2011 , p. 85). Traz questões absolutamente polêmicas que incitam fervorosas discussões no campo como o diagnóstico de Transtorno de Identidade de Gênero, a defesa da obrigatoriedade das pessoas trans de realizar acompanhamento terapêutico e o preenchimento de protocolos rígidos fundamentados em uma normalidade universal, no desvio e na doença, presentes nas Diretrizes de Assistência ao Indivíduo com Indicação para a Realização do Processo Transexualizador.

A despeito da visibilidade que as questões de gênero e sexualidade vêm assumindo nos últimos tempos e da crescente inserção de pessoas transgênero no ensino superior favorecida pelas políticas públicas e luta dos movimentos sociais na promoção da cidadania LGBT, os estigmas e estereótipos, a homofobia e transfobia frente às "performatividades estéticas alheias aos padrões binários cristalizados" (Sales et al., 2017, p. 76) impõem fronteiras no âmbito acadêmico também, pois, segundo as autoras, "os processos educativos escolares, formais e informais, deno- tam práticas, currículos e relações que afirmam tempos contínuos, processuais e regulares. As singulares e multiplicidades dos modos de vida insurgentes com outros tempos e corporalidades, rompem com estas" (Sales et al., 2017, p. 79).

Tais fronteiras se erguem muito antes do acesso ao ensino superior (Junqueira, 2010). Rondini et al. (2017), articulando vários estudos sobre estereótipos de gênero e homofobia no ensino médio, reforçam que a escola é o "locus privilegiado de aprendizado dos modelos de gênero e da higiene do sexo e, portanto, de imposição de cultura heteronormativa" (p. 59) e afirmam que as travestis e transexuais são quem mais sofrem no convívio escolar. As pesquisas que se dedicam à questão da diversidade sexual no contexto das universidades são unânimes em pontuar que se trata de um espaço de produção e reprodução da heteronormatividade, onde a homofobia está naturalizada, onde as relações de poder e hierarquias sociais estão fortemente arraigadas, havendo uma deslegitimação dos saberes e práticas de coletivos que escapam dos modelos institucionalmente valorizados e aceitos (Amaral, 2013).

Costa, Nardi e Koller (2017), ao analisar as diversas maneiras como a psicologia tratou historicamente a avaliação de gênero por meio de instrumentos de avaliação, tais como a escala de Masculinidade e Feminilidade (M) - versão brasileira da Escala de Personalidade de Comrey (CPS), concluem que a área de avaliação psicológica resiste à modificação do padrão binário classificatório, pois "o tipo de avaliação do CPS não leva em conta a autodesignação e não contribui para a construção da igualdade entre homens e mulheres, trans e cis, mas pelo contrário, trata-se de uma estratégia perigosa que restringe a autonomia dos sujeitos e reforça estereótipos arcaicos (p. 112). Concluem, alertando que

A psicologia brasileira tem sido criminosa em sua maneira de se relacionar com homens e mulheres, trans e cissexuais. Ela tem perpetuado a ideia cruel de que as pessoas não são autônomas para determinar o seu gênero, sugerindo sem bases científicas o que seria um corpo, uma identidade e uma performance de gênero normal; ela participou da prisão psicológica e física de inúmeras pessoas, especialmente trans, quando as rotulou de mentalmente incapazes por causa de sua recusa em cumprir as exigências injustas e ilegítimas impostas sobre elas (p. 112).

Diante disso, nos perguntamos: como se constituiu a trajetória de uma aluna travesti no curso de psicologia de uma universidade pública? Que enfrentamentos foram produzidos? Iniciamos essa discussão pela sua chegada ao curso que, segundo ela, foi muito complicada, envolvendo a saída de casa, a busca pela retificação do seu nome e gênero - 


\section{INTERACÃO EM LF PSICOLOGIA}

Magda Dimenstein, Emily Mel Fernandes de Souza, Jader Leite, Candida Santos e processo já mencionado que durou três anos - início do tratamento hormonal, a falta de redes de apoio, além do encontro com as profundas desigualdades econômica e social em relação aos demais alunos do curso. É uma aluna que não recebe ajuda dos pais, sobrevive de doações e com a bolsa de apoio técnico no valor de 400 reais, dos quais 150 é regularmente utilizado para a compra de hormônios, já que não dispomos de um ambulatório público especializado na região, nem a disponibilização da medicação que necessita. Segundo ela: "tenho feito meu tratamento hormonal sem acompanhamento de um endócrino, baseado em leituras de manuais de endocrinologia de sociedades internacionais e aí solicito exames de acordo com esses manuais e depois levo em um médico clínico pra ele avaliar". Sobre essas questões comenta:

"Confesso que me senti um pouco assustada quando cheguei aqui pela primeira vez, porque todos estavam tão arrumados e asseados e eu lembro que nem roupas femininas eu tinha, realmente era contrastante o nível socioeconômico... inclusive vejo colegas minhas que trocam de roupa, roupas sempre diferentes todos os dias, enquanto eu venho pra aula sempre com as mesmas calças jeans, somente duas que tenho e sempre com roupas doadas $(95 \%$ de minhas roupas são de doações feitas pelas minhas colegas e amigas)".

0 processo de ingresso na universidade e trânsito pelo curso de psicologia ao longo dos cinco anos tem sido extremamente desafiador, requerendo dela a peregrinação por muitos setores da instituição, ausentar-se de sala de aula e busca de apoio psicológico, médico e jurídico. Afirma: "Eu tive que faltar várias aulas para estar lá, isso acabou fazendo com que eu trancasse meu curso por um ano, visto que para conseguir tantos laudos e pareceres, e aí acrescenta-se audiências com promotores e juízes, eu não conseguia estar em aula e dar conta das coisas da faculdade". Porém, segundo ela, apesar da boa relação com docentes e discentes, o curso de psicologia não ofereceu nenhum apoio concreto: "Confesso que não tive ajuda da coordenação do curso em nada de meu processo de transição ou em minhas questões".

Então, quando pensamos nas barreiras de acesso e fixação no curso de alunos economicamente desfavorecidos, com ampla gama de necessidades, como é o caso da nossa protagonista, fica evidente que a chegada e permanência na universidade pública não é algo tão simples. As dificuldades a serem enfrentadas especialmente por alunos advindos das camadas populares e através das políticas de cotas vêm sendo alvo de muitos debates. Não será possível abordar a complexidade dessa questão no âmbito desse artigo. Queremos, contudo, ressaltar que além da mudança de cenário do ensino médio para o superior, os alunos precisam lidar com a dinâmica da universidade, com as mudanças pessoais que envolvem o aumento de responsabilidades e das expectativas em relação à autonomia no enfrentamento e resolução dos próprios problemas. Outro aspecto diz respeito ao encontro com a desigualdade social em cursos de ampla seletividade, como é o caso da psicologia.

A psicologia, historicamente, é um curso feito pelas elites e para as elites. Não é nenhuma novidade. 0 que queremos ressaltar com isso é que a sua estruturação como um campo de saber e práticas foi marcado por uma determinada visão de mundo e da vida social, própria dos segmentos hegemônicos e por que não dizer, das classes economicamente favorecidas. Isso significa que há um legado epistemológico e ontológico que impede nossa compreensão das várias epistemes articuladas à multiplicidade dos modos de vida e subjetivação, para além do modelo reducionista imposto pelo paradigma eurocêntrico. 0 desprezo e a derivação para a exclusão, patologização e normatização das experiências fundadas em outras lógicas é parte constituinte dos saberes científicos modernos, dos quais a psicologia é herdeira direta.

Em um ensaio sobre o impacto dos estudos e práticas políticas queer, Pocahy (2016) chama atenção para a importância dessa reflexão ao promover uma forte crítica aos jogos de saber e poder que a racionalidade científica hegemônica impõe aos corpos, sexualidades e gêneros dissidentes à norma. Os estudos queer efetuam uma crítica à centralidade dada à perspectiva relacional e heterossexual dos estudos de gênero (Galinkin, Santos, \& Zauli-Fellows, 2010). Nesse novo campo de teorização e ação política, os gêneros emergem como artefato cultural e discursivo, cabendo uma heterogeneidade de experiências performativas e uma pluralidade identitária que extrapola o binarismo sexual (Butler, 2008) presente em muitas teorizações do campo psicológico. Ao se privilegiar tal binarismo, outras formas de relação com o corpo, com as práticas sexuais e com as formas de habitar as cidades entram no cálculo do discurso patologizante.

Importante consideração feita em relação ao curso por nossa protagonista foi indicar a ausência de uma discussão sobre a temática de gênero e diversidade sexual, especialmente de matriz não essencialista, pluralista e não patológica, mostrando os efeitos do que destacamos anteriormente, ou seja, a falta de reconhecimento de mundos diferentes, e consequentemente de discussão, excluindo a possibilidade de ontologias múltiplas. Sobre isso diz: "O curso de psicologia ainda é limitado nas questões trans* e também nas questões de gênero. Sempre senti essa defasagem e sempre reclamei por uma disciplina com essa temática em todos seus módulos".

Outro aspecto que está intimamente conectado a isso é o modo de funcionamento do estágio curricular. Ela faz críticas 
a um modelo de clínica desconectada das demandas sociais, das questões de gênero e sexualidade, da problemática da violação de direitos, da produção de subjetividade na contemporaneidade. Clínica que tem a centralidade modelada em um sujeito abstrato, a-histórico e universal, que inviabiliza a expressão das diferenças e dos desvios perante à modelização massificada e serializada. Nesse sentido aponta: "Acredito que hoje esse é meu maior desafio, porque apesar muito de gostar da área clínica, essa centralidade no sujeito de certa forma me impede de ter uma atuação maior e ao mesmo tempo me angustia".

Observamos, portanto, o mal-estar produzido diante de mordaças tão ferozes, de saberes que instituem fronteiras intensivas e constrangimentos ao pensamento, aos repertórios de saber, ao cuidado de si como exercício ético (Foucault, 2004). Clínica restritiva, que aposta na objetividade e neutralidade, nos settings terapêuticos tradicionais, nos papéis estereotipados de terapeuta e paciente; clínica voltada à regulação da vida e dos corpos, prescrevendo padrões de condutas e normas de comportamento. Tal modelo é alvo de intensas críticas por seu caráter homogeneizador, reprodutor das ideologias e da infantilização das subjetividades (Guattari e Rolnik, 1986), por se apresentar na contramão das concepções que pensam em outra direção e têm outro compromisso ético: a valorização das singularidades, do intempestivo, dos movimentos, das inconstâncias, das instabilidades. Clínica que busca desestabilizar as hegemonias e perspectivas dominantes de subjetividade, buscando produzir desterritorializações. Sobre sua experiência revela:

"O serviço-escola, espaço onde realizava seu estágio curricular, é o espaço institucional vinculado ao curso de psicologia onde se materializa todas as questões anteriormente apontadas: Confesso que tive medo como as pessoas reagiriam ao ver uma pessoa trans* lá em um lugar que até hoje, a única pessoa trans* que vi lá dentro fui eu. Pode ser só uma impressão, mas quando estava só na condição de usuária/paciente/cliente do serviço eu recebia olhares, mas muito menos do que na condição de estagiária de psicologia. Também mesmo usando a camiseta do curso, porque gosto de usar por achar confortável, na condição de usuária/paciente/cliente eu não era tão interpelada pelas pessoas para saber se eu era a terapeuta. Na condição de estagiária, na qual não visto a camiseta do curso, eu vejo que sempre que as pessoas interpelam se eu sou a "psicóloga" do lugar. Será que era tão disruptivo pra uma pessoa ver uma pessoa trans* no mesmo nível que as outras pessoas? Será que eu não posso estar no lugar de terapeuta? Pensei até se essa pessoa me visse na rua, me prostituindo, será que ela teria essa reação tão cética ou simplesmente ignorasse, porque ali de certa forma é o lugar que a sociedade prega pra uma pessoa trans*?"

Exotismo, monstruosidade, inadequação, são esses os afetos que brotam na circulação de nossa narradora no serviço-escola. Local que se apresenta como um agenciador de corpos, um operador de identidades forjadas (normais e desviantes) e de relações hierárquicas e de poder. Curiosa equação que a mantém no limbo das classificações: normal enquanto paciente (por sua patologia) e desviante enquanto estagiária, pois o lugar esperado para as travestis é nas ruas e na prostituição. Mesmo usando artifícios de identificação (camisa do curso) que ilusoriamente lhe garantia uma proteção contra a violência da humilhação, da desqualificação e da falta de legitimidade no mundo acadêmico, as fronteiras intensivas e a brutalidade se erguem contra essas vidas infames, atualizando no serviço-escola um buraco negro manicomial, decalque da cidade que garante a sustentação das discursividades normatizantes e patologizantes.

\section{CONSIDERAÇÕES FINAIS}

As narrativas aqui apresentadas nos levam ao reconhecimento de uma intensa conflitualidade no tocante aos espaços institucionais da universidade. Por um lado, há constrangimentos no acesso à garantia de direitos, o que torna a circulação de pessoas trans pela instituição uma batalha pelo reconhecimento e visibilidade de si, enquanto corpo que luta por existir em meio aos padrões heteronormativos que atravessam o ambiente acadêmico. Por outro lado, há também uma certa porosidade nas fronteiras, que viabiliza a produção de um território existencial acolhedor de seu modo de diferir da norma. De acordo com a protagonista: "Acredito que toda minha resistência, empoderamento e conquistas só puderam se realizar porque tive ajuda de grandes pessoas que realmente compraram as minhas brigas".

Na produção dessas resistências, insinuações e interpelações no cotidiano acadêmico e institucional, lugar supostamente neutro, novas coreografias são postas em práticas pela composição de encontros potentes. Para Lepecki (2012), produz-se uma "coreopolítica dissensual", que transgride os sentidos de circulação na cidade e na universidade. Para ele, "toda coreopolítica requer uma distribuição e reinvenção de corpo, de afetos, de sentidos. É que toda coreopolítica revela o entrelaçamento profundo entre movimento, corpo e lugar" (p. 55). O autor segue na sua argumentação e afirma: "Como nos diz ainda Rancière (2010, p. 37, apud Lepecki, 2012, grifos nosos): 'a política consiste em transformar esse espaço de ir andando, de circulação, num espaço onde um sujeito possa aparecer'. Esse sujeito seria o ser político, ou seja, aquele que é capaz de exercitar a sua [sempre presente] potência para o dissenso, que é um exercício também fundamentalmente estético, não arregimentado por vetores de sujeitificação pré-dados" (Lepecki, 2012, p.56). 


\section{INTERAÇÃO EM PSICOLOGIA}

Magda Dimenstein, Emily Mel Fernandes de Souza, Jader Leite, Candida Santos e João Paulo Macedo
Assim, as travestis com seus corpos transgressores da cisnormatividade e heteronormatividade compulsória evidenciam "o sujeito que emerge entre as rachaduras do urbano, movendo-se para além e aquém dos passos que the teriam sido pré-atribuídos" (Lepecki, 2012, p. 57) e apresentam potencial político e capacidade de rearranjos do espaço público, da relação corpo-cidade, inventando curtos-circuitos e agitação nas linhas duras que controlam as cidades e subjetividades no cotidiano.

\section{CONTRIBUIÇÃO DE CADA AUTORES:}

Certificamos que todos os autores participaram suficientemente do trabalho para tornar pública sua responsabilidade pelo conteúdo. A contribuição de cada autor pode ser atribuída como se segue:

M.D, J.L e C.D contribuíram para a conceitualização, investigação e visualização do artigo; M.D e J.L fizeram a redação inicial do artigo (rascunho) e M.D, E.M.S, J.L, C.D e J.P.M são os responsáveis pela redação final (revisão e edição).

\section{DECLARAÇÃO DE CONFLITOS DE INTERESSE:}

Os autores declaram que não há conflitos de interesse no manuscrito submetido.

\section{REFERÊNCIAS}

Amaral, J. G. (2013). Lutas por reconhecimento, desrespeito e universidade: A atuação dos coletivos universitários de diversidade sexual para o enfrentamento à homofobia institucional. Revista Teoria \& Sociedade, 12(2).

Bento, B. (2011). Resistência globalizada contra o diagnóstico de gênero. In Conselho Federal de Psicologia (Org.), Psicologia e diversidade sexual: Desafios para uma sociedade de direitos (pp. 77-88). Brasília: Conselho Federal de Psicologia.

Bento, B. (2014). Estudos de gênero: O universal, o relacional e o plural. In B. Bento (Org.), A reinvenção do corpo: Sexualidade e gênero na experiência transexual (pp. 69-108). Rio de Janeiro: Garamond.

Butler, J. (2000). Corpos que pesam: Sobre os limites discursivos do "sexo". In G. L. Lopes (Org.), O corpo educado: Pedagogias da sexualidade (pp. 153-172). Belo Horizonte. Autêntica.

Butler, J. (2008). Cuerpos que importan: Sobre los límites materiales y discursivos del "sexo". Buenos Aires: Paidós.

Costa, A. B., Nardi, H. C., \& Koller, S. H. (2017). Manutenção de desigualdades na avaliação do gênero na psicologia brasileira. Temas em Psicologia, 25(1), 97-115. doi: https:// dx.doi.org/10.9788/TP2017.1-06.
Costa, A. B., Peroni, R. O., Camargo, E. S., Pasley, A., \& Nardi, H. C. (2015). Prejudice toward gender and sexual diversity in a Brazilian public university: Prevalence, awareness, and the effects of education. Sexuality Research and Social Policy, 12 (4), 261-272.doi: http://dx.doi.org/10.1007/ s13178-015-0191-z.

Cruz, E. F. (2011). Banheiros, travestis, relações de gênero e diferenças no cotidiano da escola. Revista Psicologia Política, 11(21), 73-90.

Deleuze, G. (2000). Conversações. São Paulo: Editora 34.

Dimenstein, M. (2007). "Da água estagnada espera veneno": Compromissos éticos e políticos em Psicologia. In M. A. T. Ribeiro, J. S. Bernardes, \& C. E. Lang. (Orgs.), A produção na diversidade: Compromissos éticos e políticos em Psicologia (pp. 183-196). São Paulo: Casa do Psicólogo.

Foucault, M. (1990). Microfísica do poder. Rio de Janeiro: Edições Graal.

Foucault, M. (2004). A ética do cuidado de si como prática da liberdade. In M. B. Motta (Org.), Ditos \& Escritos V: Ética, Sexualidade, Política (pp. 45-78). Rio de Janeiro: Forense Universitária.

Foucault, M. (2010). Os anormais. São Paulo: Martins Fontes.

Franco, N., \& Cicillini. G. A. (2015). Professoras trans brasileiras em seu processo de escolarização. Estudos Feministas, 23(2), 325-346.

Galinkin, A. L., Santos, C., \& Zauli-Fellows, A. (2010). Estudos de gênero na psicologia social. In A. L. Galinkin \& C. Santos (Orgs), Gênero e psicologia social: Interfaces (pp. 503558). Brasília: Technopolitik.

Guattari, F. (1992). Caosmose: Um novo paradigma estético. São Paulo: Editora 34.

Guattari, F., \& Rolnik, S. (1986). Micropolítica: Cartografias do desejo. Rio de Janeiro: Editora Vozes.

Junqueira, R. D. (2010). Currículo heteronormativo e cotidiano escolar homofóbico. Espaço do Currículo, 2(2), 208-230.

Lepecki, A. (2012). Coreopolítica e coreopolícia. Ilha, 13(1), 41-60.

Madureira, A. F. A., \& Branco, A. U. (2015). Gênero, sexualidade e diversidade na escola a partir da perspectiva de professores/as. Temas em Psicologia, 23(3), 577-591.

Pechman, R. M. (2009). 9 cenas, algumas obs-cenas, da rua. Fractal: Revista de Psicologia, 21(2), 351-368.

Peixoto Júnior, C. A. (2010). Sobre corpos e monstros: Algumas reflexões contemporâneas a partir da filosofia da diferença. Psicologia em Estudo, 15(1), 179-187.

Pelbart, P. P. (2013). O avesso do niilismo - cartografias do esgotamento. São Paulo: N-1 Edições.

Pocahy, F. (2016). (Micro)políticas queer: Dissidências em pesquisa. Textura, 18(38), 9-25.

Prado, M. A. M., \& Junqueira, R. D. (2011). Homofobia, hierar- 


\section{N"INTERACÃO EM ET. PSICOLOGIA}

quização e humilhação social. In G. Venturi, \& V. Bokani (Orgs.), Diversidade sexual e homofobia no Brasil (pp. 5172). São Paulo: Editora Fundação Perseu Abramo.

Preciado, B. (2014). Manifesto contrassexual: Políticas subversivas de identidade sexual. São Paulo: N-1 Edições.

Rocha, L. L. F. (2013). o que a história do monstro humano pode nos contar da monstruosidade da vilania e seu embelezamento. Anais do $9^{\circ}$ Encontro Nacional de História da Mídia (p.15). Ouro Preto, Minas Gerais. Recuperado em 10 de novembro de 2017, de http://www.ufrgs.br/alcar/ encontros-nacionais-1/9o-encontro-2013/artigos/gthistoria-da-midia-audiovisual-e-visual/o-que-a-historia-domonstro-humano-pode-nos-contar-da-monstruosidade-davilania-e-seu-embelezamento.

Rodrigues, H. B. C. (2009). Para desencaminhar o presente psi: Biografia, experiência e temporalidade em Michel Foucault. In N. M. F. Guareschi, \& S. M. Hüining (Orgs.), Foucault e a Psicologia (pp. 07-30). Porto Alegre: EDIPUCRS.

Rondini, C. A., Teixeira Filho, F. S., \& Toledo, L. G. (2017). Concepções homofóbicas de estudantes do ensino médio. Psicologia USP, 28(1), 57-71. doi: https://dx.doi.org/ 10.1590/0103-656420140011.
Rossi, A., \& Passos, E. (2014). Análise institucional: Revisão conceitual e nuances da pesquisa-intervenção no Brasil. Revista EPOS, 5(1), 156-181.

Secretaria de Direitos Humanos (2013). Relatório sobre violência homofóbica no Brasil: Ano de 2012. Brasilia: Autor.

Sales, A., Souza, L. L., \& Peres, W. S. (2017). Travestis brasileiras e escola: Problematizações sobre processos temporais em gêneros, sexualidades e corporalidades nômades. Fractal: Revista de Psicologia, 29(1), 71-80. doi: https:// doi.org/10.22409/1984-0292/v29i1/1530.

Toneli, M. J., \& Amaral, M. S. (2013). Sobre travestilidades e políticas públicas: Como se produzem os sujeitos da vulnerabilidade. In H. C. Nardi, R. S. Silveira, \& P. S. Machado (Orgs.), Diversidade sexual, relações de gênero e políticas públicas (pp. 32-48). Porto Alegre: Sulina.

Submetido em 20/10/2017

Primeira decisão editorial em 09/04/2018

Aprovado em 17/04/2018

Notas

$1 \mathrm{Na}$ referida instituição, há cerca de 10 pessoas trans autodeclaradas ou não em um universo de 37 mil estudantes.

2 Ver: https://site.cfp.org.br/wp-content/uploads/2011/05/Diversidade_Sexual_-_Final.pdf 